\title{
Editorial commentary: The anatomical basis of prosopagnosia-facial blindness, do you see what I see?
}

\author{
Rebekah M Ahmed, ${ }^{1}$ John R Hodges ${ }^{2}$
}

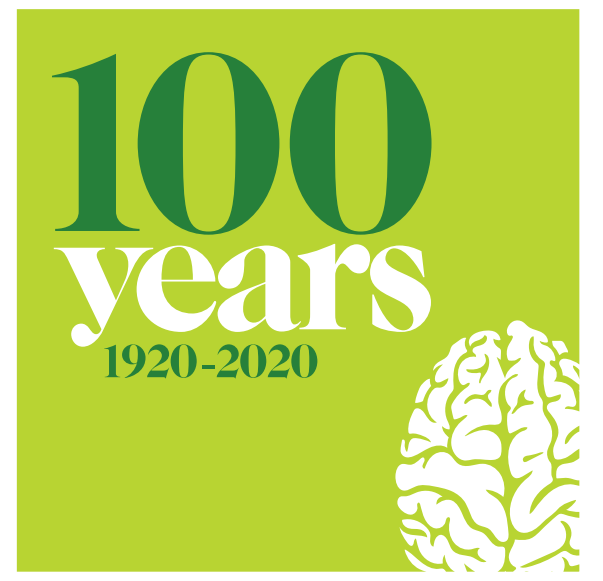

JC Meadows 1974 paper entitled 'The anatomical basis of prosopagnosia' reminds us that past observations and data can often provide the basis for our understanding of complex neurological conditions today. The utility of clinical observations to aid in anatomical localizsation cannot be underestimated.

'The anatomical basis of prosopagnosia' is a concept that has intrigued neurologists and neuropsychologists since the first descriptions of prosopagnosia in the 19th century by Quaglino and subsequently by the giants of early neurology Hughlings Jackson and Charcot. ${ }^{2} 3$ The JNNP has a long history of publishing manuscripts discussing this phenomenon that have included case reports by illustrious authors such as Elizabeth Warrington ${ }^{4}$ and also historical notes ${ }^{2}$ detailing Lewis Carroll's humpty dumpty in Through the looking-glass, and what Alice found there (1872), as an early report of prosopagnosia. John Meadows in his comprehensive review published in $1974^{1}$ has been cited more than 400 times, which speaks

${ }^{1}$ Memory and Cognition Clinic, Department of Clinical Neurosciences, Royal Prince Alfred Hospital, Sydney, New South Wales, Australia

${ }^{2}$ The University of Sydney, Central Sydney Medical School and Brain \& Mind Centre, Sydney, New South Wales, Australia

Correspondence to Dr Rebekah M Ahmed, Brain and Mind Centre, University of Sydney, 94 Mallet St, Camperdown, Sydney, NSW 2050, Australia; Rebekah. ahmed@sydney.edu.au
The anatomical basis of prosopagnosia

Authors: J. C. Meadows

Year published: 1974

Number of times cited: 433

to the enduring interest in this disorder. The review provides an in-depth discussion of aspects of prosopagnosia that continue to intrigue researchers and clinicians. It is fascinating to re-read this paper written 45 years ago and realise that many of the issues raised are still relevant and that (correct) anatomical conclusions could be reached based on such primitive data. The original data on prosopagnosia were based on acute insults to the brain for example, stroke and tumours, but more recent research building on these original observations has led to a body of research examining progressive forms of prosopagnosia in neurodegeneration and to the discovery of congenital prosopagnosia.

Prosopagnosia is a rare condition defined as the specific inability to recognise familiar faces even those of highly familiar people such as family members. Meadows in his 1974 paper $^{1}$ discusses key issues including the exact definition of prosopagnosia, the cognitive basis particularly the issue of whether prosopagnosia is a deficit in memory, and the anatomical basis of prosopagnosia especially the question of whether lesions need to be bilateral.

Meadows ${ }^{1}$ discusses the ability to recognise faces as one of the 'most complex and sophisticated visual achievements' that one can achieve. He discusses the debate, which was of considerable interest at the time, as to whether prosopagnosia is specific to faces or can involve other categories with multiple similar exemplars. For instance, the case of a farmer with prosopagnosia who was reported to have lost the ability to recognise the faces of his cows, suggesting that it is a disorder of visual recognition, when there are multiple stimuli, all of which are very similar, rather than being specific to faces. Although there have been counter reports, the issue of specificity remains unresolved.

The main contribution of Meadows paper ${ }^{1}$ was the comprehensive review of the available imaging and necropsy data available in 1974 concerning the anatomical basis of prosopagnosia. Virtually all cases were found to have a right occipitotemporal lesion involving the fusiform and/or lingual gyrus with a left upper quadrantic visual field defect. He reviews the evidence for whether lesions need to be bilateral or can be unilateral, and reports that the majority of cases tend to be bilateral, but that the left-sided lesions do not necessarily have to involve the occipitotemporal region. Importantly there were cases with localised right-sided lesions suggesting that the right-sided lesions are critical to the genesis of prosopagnosia. It is remarkable that this evidence was based on early CT scan and radio isotope imaging with their known imperfections. The conclusion has stood the test of time and has been confirmed in the MRI era.

Meadows discusses issues concerning the cognitive basis of prosopagnosia and whether it should be considered a memory deficit. It should be remembered that the paper was written before the widespread acceptance of the distinction between episodic and semantic memory first proposed by Endel Tulving in the early $1970 \mathrm{~s}^{5}$ and the seminal description of circumscribed semantic memory loss by Elizabeth Warrington in $1975 .^{6}$ Given the fact that even the most densely amnesic patient can recognise loved ones and that elements of autobiographical memory are intact in patients with prosopagnosia, it clearly cannot be regarded a disorder of episodic memory. The question of whether it represents a category specific form of semantic memory loss was, understandably, not discussed, but as outlined below we now know that there is a specific form of the syndrome in which knowledge of people is lost, but this is distinct from the traditional form of prosopagnosia which arises following acute strokes or damage to the posterior temporal lobe(s).

The review was also written at a time when tests of face perception and 
identification were in their infancy and models of face processing were yet to be developed. The review did, however, draw attention to this fascinating syndrome and raised questions about the underlying cognitive basis which culminated, a decade later, in the influential model of theories of parallel and sequential face processing by Bruce and Young ${ }^{7}$ and the subsequent realisation that prosopagnosia may be associated with a range face processing deficits and cannot be considered a singular entity. In recent times there have been the development of concepts of apperceptual and associative forms of prosopagnosia. ${ }^{8}$

Another long-term outcome of this early literature has been the recognition of the syndrome of developmental prosopagnosia, ${ }^{8}$ in which subjects fail to develop facial recognition skills, but have normal high-level visual skills and memory. Although described in the 1970 s, ${ }^{9}$ it was felt for many years to be exceedingly rare and gained little attention. The developmental form of 'face blindness' appears, however, to be far commoner than the acquired version and was highlighted in a very recent BBC Radio 4 interview with Stephen Fry (https://www.bbc.co.uk/ programmes/p04d7jcs).

Patients with traditional acquired poststroke prosopagnosia may wake up in hospital with a stranger sitting by their bedside, who they then realise is their spouse after he, or she, starts to speak. They learn to recognise people from their hairstyle, dress and voice and, importantly, retain their knowledge of people and can answer questions about Donald Trump or Boris Johnson, demonstrating retained semantic knowledge of people. By contrast, a syndrome of progressive prosopagnosia with gradual erosion of person knowledge and affecting all modalities of input and beginning with less familiar and encountered individuals in association with right anterior temporal lobe atrophy was first reported in $1995^{10}$ as the counterpart to progressive left anterior temporal lobe degeneration and we now know as semantic dementia. ${ }^{11}$ Over the last 20 years, the syndrome of right anterior temporal lobe atrophy has been further described with prominent behavioural features, including disinhibition, lack of insight and abnormal social conduct occurring alongside prosopagnosia, and given the name of right semantic dementia, a form of frontotemporal dementia. ${ }^{11} 12$ Studies have examined the long-term progression between right versus left semantic dementia ${ }^{13}$ and found that patients with left-sided semantic dementia which initially starts as a language syndrome in the left anterior temporal lobe develop prominent changes in behaviour with disease progression, as the anterior right temporal lobe becomes involved. Those with right-sided semantic dementia show loss of language abilities with disease progression and involvement of the left temporal lobe. The fact that different brain regions and cognitive processes are involved in facial recognition as opposed to the identification of facial emotions has gained traction with the explosion of interest in emotion processing particularly in frontotemporal degeneration.

The concepts highlighted by Meadows concerning the role of posterior temporal lobes in aspects of high-level visual processing and the recognition of complex visual stimuli remain current. His scholarly review of the anatomical data from in vivo and pathological studies showed the strength of this approach, which we might now refer to as a form of meta-analysis, and it is significant that his conclusions have very clearly stood the test of time. It is easy to underestimate the importance of facial recognition, yet in an everchanging world, facial recognition forms the bases of social profiling and automated methods of face recognition which is in turn relevant to increasing applied security measures, meaning that understanding of this complex visual processing task is paramount.
Contributors RMA and JRH both drafted and reviewed manuscript.

Funding The authors have not declared a specific grant for this research from any funding agency in the public, commercial or not-for-profit sectors.

Competing interests None declared.

Patient consent for publication Not required.

Provenance and peer review Commissioned; internally peer reviewed.

(c) Author(s) (or their employer(s)) 2020. No commercial re-use. See rights and permissions. Published by BMJ.

\section{Check for updates}

To cite Ahmed RM, Hodges JR. J Neurol Neurosurg Psychiatry 2020;91:451-452.

Received 16 December 2019

Accepted 4 January 2020

J Neurol Neurosurg Psychiatry 2020;91:451-452. doi:10.1136/jnnp-2019-322384

\section{REFERENCES}

1 Meadows JC. The anatomical basis of prosopagnosia. J Neurol Neurosurg Psychiatry 1974;37:489-501.

2 Larner AJ. Lewis Carroll's Humpty Dumpty: an early report of prosopagnosia? I Neurol Neurosurg Psychiatry 2004;75:1063.

3 Quaglino A, Borelli GB, Della Sala S, et al. Quaglino's 1867 case of prosopagnosia. Cortex 2003;39:533-40.

4 Whiteley AM, Warrington EK. Prosopagnosia: a clinical, psychological, and anatomical study of three patients. $J$ Neurol Neurosurg Psychiatry 1977;40:395-403.

5 Tulving E, Donaldson W, Bower GH, et al. Office of naval research. organization of memory. New York: Academic Press, 1972.

6 Warrington EK. The selective impairment of semantic memory. Q J Exp Psychol 1975;27:635-57.

7 Bruce V, Young A. Understanding face recognition. $\mathrm{Br}$ J Psychol 1986;77:305-27

8 Corrow SL, Dalrymple KA, Barton JJ. Prosopagnosia: current perspectives. Eye Brain 2016:8:165-75.

9 McConachie HR. Developmental prosopagnosia. A single case report. Cortex 1976;12:76-82.

10 Evans JJ, Heggs AJ, Antoun N, et al. Progressive prosopagnosia associated with selective right temporal lobe atrophy. A new syndrome? Brain 1995:118:1-13.

11 Thompson SA, Patterson K, Hodges JR. Left/ right asymmetry of atrophy in semantic dementia: behavioral-cognitive implications. Neurology 2003:61:1196-203.

12 Chan D, Anderson V, Pijnenburg Y, et al. The clinical profile of right temporal lobe atrophy. Brain 2009;132:1287-98.

13 Kumfor F, Landin-Romero R, Devenney E, et al. On the right side? A longitudinal study of leftversus right-lateralized semantic dementia. Brain 2016;139:986-98. 